\title{
Low Back Pain and Obesity
}

\author{
Dafina Ibrahimi-Kaçuri, Ardiana Murtezani, Shkurta Rrecaj, Merita Martinaj, Bekim Haxhiu
}

\author{
Occupational Medicine Institute, Obiliq, Kosovo
}

Corresponding author: Ardiana Murtezani, MD, PhD. University Clinical Centre of Kosova, Rr. e spitalit pn. 10000 Prishtina, Republic of Kosovo. E-mail: ardianaa@yahoo.com

\begin{abstract}
Introduction: Low back pain poses a significant problem in clinics and public health. It presents one of the main problems with adults, since $70-80 \%$ of adults experience it at least once in their lifetime. Causes of the low back pain are numerous and often unknown. Objectives: The aim of the study is to find the most prevalent age group, pain localisation, and the frequency of physical therapy sessions in obese and non-obese subjects with LBP. Materials and Methods: The study has been conducted by the Physical Rehabilitation Service of the Occupational Medicine Institute, during one year period. The total number of patients studied was 101 and all were Kosovo Energy Corporation (KEC) employees. The study was retrospective. Results: Looking at the body weight index, out of 101 patients, $69.3 \%$ are classified as non-obese and $30.7 \%$ as obese. Using T-Test we have found a difference of high statistical significance between the average number of the physical therapy sessions applied in relation to the examined groups ( $\mathrm{T}-\mathrm{Test}=2.78, \mathrm{P}=0.0065$, so, $\mathrm{P}<0.01$ ). Conclusion: Obesity and age have no direct influence in back pain, but they could prolong healing. Professional occupation and binding position are factors that affect back pain. Physical workload can cause the manifestation of sciatica; whereas psycho-social factors can prolong the overall healing process.
\end{abstract}

Key words: Low back pain, obesity, physical therapy.

\section{INTRODUCTION}

Low back pain (LBP) is a symptom, not a disease (1). This may be due to degenerative processes of the spine axis, various trauma, occupational position (2) and congenital malformations. Very often we find in literature review that a widespread cause is also obesity $(1,3)$. Back pain in the lumbar area is a widespread problem in the world's population, approximately 70-80\% of the people suffer from it at least once in their life-time. Low back pain is a pain that manifests itself in the lumbar region and may also include the sciatic nerve $(1,3)$. Back pain is classified as acute and chronic. Its treatment is carried out in several ways depending on the stage the patient is. Handling goes through the stages such as: drug treatment and physical therapy. The goals of rehabilitation are: patient education; pain control and inflammation reduction; early mobilization; the application of physiotherapy exercises; reaching the full amplitude of movement without pain in the injured region; strengthening, endurance and coordination; the restoration of normal life activities; the prevention of illness relapse and other injuries (4).

\section{OBJECTIVES}

The aim of the study is to find the most prevalent age group among the obese and non-obese subjects with LBP; the most prevalent pain localisation among the obese and non- obese subjects with LBP, and the frequency of physical therapy sessions in obese and non-obese subjects.

\section{MATERIAL AND METHODS}

This study was conducted in Physical and Rehabilitation Medicine Service in the Occupational Medicine Institute (OMI) during one year period, throughout 2013. The total number of patients involved in the research was 101, their average age was 50, while the average work experience, 24 years, all employed at the Kosovo Energy Corporation (KEC). Criteria for inclusion in the research were: a confirmed LBP diagnosis, being KEC employee and involved in physical work. Avoidance criteria of research were: Female patients; patients registered at OMI but not working at KEC; non-diagnosed patients albeit complaining from back pain. The research was retrospective, comparative. The material was studied according to the protocol. Subjective data were obtained, such as; age, gender, work experience, and profession. Objective data, such as specific tests (Lasegue test, extension-flexion test, pressure test in the anterior superior iliac spine) and diagnosis were made by a specialist of physical and rehabilitation medicine, while $\mathrm{x}$-ray pictures were examined by the radiologist. The physical therapy was applied as advised by the protocol book. The patients were treated with physical therapy at OMI. All 101 patients underwent physical therapy. 
Kinesitherapy was applied according to the protocol of McKenzie (5) in a standardized protocol and tailor made for each case. In general, kinesitherapy has focused on static and dynamic exercises to strengthen the muscles of the lumbar region, abdominal, pelvic muscles, spine, and in general extremities, especially legs.

Body mass index (BMI) was calculated as weight (in kilograms) divided by height (in meters) squared. BMI values are classified as follows: $<18.9-$ underweight, 19- 24.9 -normal 25-29.9-overweight and $>30$-obese.

\subsection{Ethical clearance}

The study was approved by the Regional Ethical Board of the Institute of Occupational Medicine, Kosovo. Written informed consent of each participant was obtained along with the approval of the Kosovo Energy Corporation administration.

\subsection{Statistical analysis}

Data was presented using tables and graphs. Data processing was done with Office 2007 Excel. From statistical parameters the following were calculated: the index structure, the arithmetic mean, standard deviation, and minimum/maximum values. For data testing in non-parametric test $\mathrm{X}^{2}$ and Fisher tests were used, while for parametric data the T-test was used. Verification of tests for confidence level of $95 \%$ is ( $\mathrm{p}<0: 05)$.

\section{RESULTS}

The research included 101 patients with LBP, of which 70 or $69.3 \%$ according to body mass index are classified as non-obese and 31 or $30.7 \%$ as obese (Table 1). The largest number of patients $(48.5 \%)$ belonged to the age group 45 54 years. As for the relationship between groups and age group, we did not find significant differences, except for the age group 25-34 years, where the largest number of patients belonged to the non-obese group (10\%).

\begin{tabular}{|c|c|c|c|c|c|c|c|}
\hline \multirow{2}{*}{$\begin{array}{l}\text { Age group } \\
\text { (years) }\end{array}$} & & \multicolumn{2}{|c|}{$\begin{array}{l}\text { Group } 1 \text { (not } \\
\text { obese) }\end{array}$} & \multicolumn{2}{|c|}{$\begin{array}{l}\text { Group } 2 \\
\text { (Obese) }\end{array}$} & \multicolumn{2}{|l|}{ Total } \\
\hline & & $\mathrm{N}$ & $\%$ & $\mathrm{~N}$ & $\%$ & $\mathrm{~N}$ & $\%$ \\
\hline $25-34$ & & 7 & 10.0 & 1 & 3.2 & 8 & 7.9 \\
\hline $35-44$ & & 8 & 11.4 & 5 & 16.1 & 13 & 12.9 \\
\hline $45-54$ & & 35 & 50.0 & 14 & 45.2 & 49 & 48.5 \\
\hline $55+$ & & 20 & 28.6 & 11 & 35.5 & 31 & 30.7 \\
\hline \multirow{2}{*}{ Total } & $\mathrm{N}$ & 70 & 100.0 & 31 & 100.0 & 101 & 100.0 \\
\hline & $\%$ & 69.3 & - & 30.7 & - & 100.0 & - \\
\hline
\end{tabular}

Table 1. The age group of subjects with low back pain in Group I and II

Of the total number of patients included in research ( $n=101$ ) only 64 or $63.4 \%$ had pain in the lower back. The obese patients had only pain in lumbosacral region in higher percentage, $80.6 \%$, compared to $55.7 \%$ of nonobese patients, who also complained of pain more frequently (Table 2). More than half of the patients included in the research (70 or $69.3 \%$ ) had 10 or more sessions of physical therapy out of which the obese group was higher in structure compared to the non-obese group (80.6\% vs. $64.3 \%$ ), (Table 3 ). The average number of physical therapy sessions of the research patients was 10.32 ( $\mathrm{SD} \pm 5.22$ ). The smaller number of sessions applied to the patients involved in the research was two sessions and 30 sessions

\begin{tabular}{|c|c|c|c|c|c|c|}
\hline \multirow{2}{*}{ Pain localisation } & \multicolumn{2}{|c|}{$\begin{array}{l}\text { Group } 1 \\
\text { (not obese) }\end{array}$} & \multicolumn{2}{|c|}{$\begin{array}{l}\text { Group } 2 \\
\text { (Obese) }\end{array}$} & \multicolumn{2}{|c|}{ Total } \\
\hline & $\mathrm{N}$ & $\%$ & $\mathrm{~N}$ & $\%$ & $\mathrm{~N}$ & $\%$ \\
\hline $\begin{array}{l}\text { Back pain that radiates } \\
\text { down the back of the } \\
\text { thigh }\end{array}$ & 3 & 4.3 & - & - & 3 & 3.0 \\
\hline Low back pain & 39 & 55.7 & 25 & 80.6 & 64 & 63.4 \\
\hline $\begin{array}{l}\text { Back pain that radiates } \\
\text { from the low back to the } \\
\text { buttock }\end{array}$ & 17 & 24.3 & 2 & 6.5 & 19 & 18.8 \\
\hline $\begin{array}{l}\text { Back pain that radiates } \\
\text { into the calf and toes }\end{array}$ & 11 & 15.7 & 4 & 12.9 & 15 & 14.9 \\
\hline Total & 70 & 100.0 & 31 & 100.0 & 101 & 100.0 \\
\hline
\end{tabular}

Table 2. The pain localization among subjects in Group I and II

\begin{tabular}{lllllll}
\hline $\begin{array}{l}\text { Physical } \\
\text { therapy } \\
\text { sessions }\end{array}$ & \multicolumn{2}{l}{ Group 1 (not obese) } & \multicolumn{2}{l}{ Group 2 (Obese) } & \multicolumn{2}{l}{ Total } \\
\cline { 2 - 7 } & $\mathrm{N}$ & $\%$ & $\mathrm{~N}$ & $\%$ & $\mathrm{~N}$ & $\%$ \\
\hline$<10$ & 25 & 35.7 & 6 & 19.4 & 31 & 30.7 \\
\hline $10+$ & 45 & 64.3 & 25 & 80.6 & 70 & 69.3 \\
\hline Total & 70 & 100.0 & 31 & 100.0 & 101 & 100.0
\end{tabular}

Table 3. The number of physical therapy sessions in Group I and II

the largest. The average number of physical therapy sessions of the research patients of non-obese group was 9.39 sessions ( $\mathrm{SD} \pm 4.81$ ). The smaller number of sessions applied to the patients of this group was two sessions, and the largest 30 sessions. The average number of physical therapy sessions of the research patients of obese group was 12.42 sessions ( $\mathrm{SD} \pm 5.57$ ). The smallest number of sessions applied to obese patients was five, and the largest 25 sessions. With the T-test of average we have gained high distinction with statistical significance between the average number of sessions applied by groups ( $\mathrm{t}$-test $=$ 2.78, $\mathrm{P}<0.01$ ) (Table 4).

\begin{tabular}{llll}
\hline & Group 1 (not obese) & Group 2 (Obese) & Total \\
\hline $\mathrm{N}$ & 70 & 31 & 101 \\
\hline Average & 9.39 & 12.42 & 10.32 \\
\hline Standard Dev. & 4.81 & 5.57 & 5.22 \\
\hline Min & 2 & 5 & 2 \\
\hline Max & 30 & 25 & 30 \\
\hline
\end{tabular}

T-test, $\mathrm{P}$-value $\quad \mathrm{t}=2.78, \mathrm{P}=0.0065$

Tabela 4. The average number of physical therapies in Group I and II

\section{DISCUSSION}

Pain in the lower back poses significant problem in clinical and public health, being one of the main problems in adults. The causes of back pain are numerous, and often unknown. Obesity is a result of poor life-style, which affects the deterioration of back pain. Miranda et al (6) have come to the conclusion that among patients of different ages, LBP risk factor varies by age groups. In our research only male patients are included whose average age was 50 years old. Related data were also found by Bener et al. (7), whereas Chemeris et al. (8) confirmed that the average age of patients with back pain has been 40 years. 
Back pain and obesity: There have been many studies worldwide about how obesity $(\mathrm{OB})$ affects the problem in the spinal pain, where we found different opinions regarding this issue. Mirtz et al. (9) have conducted a paper in Kansas in United States of America by reviewing the literature in Medline. They have come to the conclusion that there is a great uncertainty in the theory of the impact of obesity in the back pain. Loss of muscle mass of the trunk and muscles of lower extremities and central OB may be a risk factor for back pain (10). Melissa et al. (11) found that out of 29 patients with back pain who had problem with obesity have discovered that the removal of body weight through surgical procedures improves the function of disability to those who suffer from back pain. Similarly with this the Al-Shamari et al. (12) have concluded that $\mathrm{OB}$ affects back pain. Obesity prevalence is higher among women, housewives, the divorced, widows and those who reside in rural areas. Bolgen et al. (13) have come to the conclusion that obesity has not been the cause of severe pain in patients with back pain, but excessive obesity has contributed to the difficulties of performing the daily life functions. Contrary to these papers Manchikanti et al. (14) have studied two groups of obese and non-obese patients and concluded that the incidence of pain in the facets joints was the same in both groups. Similarly McCarthy et al.(15) also have come to the conclusion that out of 840 patients with chronic back pain there was similarity in results with both groups, obese and non-obese, although female gender had greater tendency for the impact of obesity. Also Ibraimi et al (16) in their research concluded that no association was found between weight and height and the prevalence rate of LBP among industrial workers. In our paper we have not found any significant difference of the impact of obesity in back pain.

Physical Therapy: Physical exercise may be helpful for patients with chronic back pain to return to normal daily activities and work $(17,18)$. Application of regular 3-4 a week exercise is the best solution for reducing the level of back pain (19). Factors that contribute to prolonging the recovery from back pain are: age, localization of pain and socioeconomic and psychological factors (20). Mangvani et al. (21) in their research has shown that obesity did not present significant difference in treatment with physical therapy to eliminate pain. On the other hand, in our study we've gained a large statistical significance during application of physical therapy based on groups ( $\mathrm{t}$-test $=2.78, \mathrm{P}<0.01)$ where the obese group had a higher average of application of physical therapy compared to non- obese group. So, in average, the obese group has used more physical therapy sessions compared to that of non-obese. Similar to our study, Hooper et al. (22) has concluded that weight loss helps in the treatment of patients with osteomuscular problems.

Limitations: Due to the issue of the place where the research was conducted we have not been able to make comparisons between the genders. According to the papers of many authors, due to obesity the female gender tends to be more at risk from back pain.

\section{CONCLUSIONS}

Obesity and age have no direct effect on back pain, but they could prolong the duration of recovery. We as a country are still developing and have maintained the nutrition pattern, with a tendency to change, therefore the value of BMI is small in comparison with the developed countries. Therefore, it would be very beneficial to organize a campaign to raise awareness of the population about obesity and the problems it causes. Losing weight helps in the treatment of patients with osteomuscular problems. Occupation and obligatory positions are factors that influence back pain. Physical exertion at work affects the appearance of pain along the sciatic nerve, and psychosocial factors affect the duration of recovery.

\section{CONFLICT OF INTEREST: NONE DECLARED.}

\section{REFERENCES}

1. Wong D, Transfeldt E, Macnab I, McCulloch J. Macnab's backache. Philadephia, Williams \& Wilkins, 2007.

2. Tiric-Campara M, Krupic F, Biscevic M, Spahic E, Maglajlija K, Masic Z, Zunic L, Masic I. Occupational overuse syndrome (Technological diseases): carpal tunnel syndrome, a mouse shoulder, cervical pain syndrome. Acta Inform Med. 2014 Oct; 22(5): 333-340.

3. Szpalski M, Gunzburg R, Rydevik B. Surgery for Low Back Pain. Verlag, Berlin, Hidenberg, Springer, 2010.

4. De Lisa A J, Rehabilitation Medicine, Principles and Practice, Philadelphia, J.B.Lippincot Company, 1988.

5. McKenzie R.Treat your own back. Seventh Edition, New Zealand, Spinal Publications, 1997.

6. Miranda H, Viikari JE, Punnette L, Riihimaki H. Occupational loading, health behavior and sleep disturbance as predictors of low-back pain. Scand J Work Environ Health. 2008; 34(6): 411-419.

7. Bener A, Alwash R, Gaber T, Lovasz G. Obesity and low back pain. Coll Antropol. 2003 Jun; 27(1): 95-104.

8. Chemeris N. Prevalence and recovery rate of low back pain and leg pain in osteopathic practice. (Master's thesis). Unitec New Zealand. 2008; 1-62.

9. Mirtz T, Greene L. Is obesity risk factor for low back pain? An example for using the evidence to answer a clinical question. Chiropr Osteopat. 2005; 13:2.

10. Toda Y, Segal N, Toda T, Morimoto T, Ogawa R. Lean body mass and body fat distribution in participants with chronic low back pain. Arch Intern Med. 2000 Nov 27; 160(21): 3265-3269.

11. Melisa J, Kontakis G, Volakakis E, Tsepetis T, Alegakis A, Hadjipavlou A. The Effeect of Surgical Weight Reduction on Functional Status in Morbidly Obese Patients with Low Back Pain. Obes Surg. 2005 Mar; 15(3): 378-381.

12. Al-Shamari SA, Khoja TA, Kremli M, Al-Balla SR. Low back pain and obesity in primary helath care. Saudi Med J. 1994; 15: 223-226.

13. Kaaria S, Leino-Arjas P, Rahkonen O, Latí J, Lahelma E, Laaksonen M. Risk factors of sciatic pain: A prospective study among middle-aged employees. Eur J Pain. 2011 Jul; 15(6): 584-590

14. Manchikanti L, Pampati V, Singh V, Beyer C, Damron K, Fellows B. Evaluation of Role of Facet Joints in Persistent Low Back Pain in Obesity: A Controlled, Prospective, Comparative Evaluation. Pain Physician. 2001; 4(3): 266-272.

15. McCarthy L, Bigal M, Katz M, Derby C, Lipton R. Chronic Pain And Obesity in the Elderly: Results from the Einstein Aging Study. J Am Geriatr Soc. Jan 2009; 57(1): 115-119.

16. Ibraimi Z, Murtezani A, Haxhiu B, Mustafa A, Martinaj M. Prevalence and pharmacologic treatment of patients with low back pain treated at Kosovo energetic corporation. Med Arch. 2013 Dec; 67(6): 410-413.

17. Gracey JH, McDonough SM, Baxter GD. Physiotherapy management of low back pain: A survey of current practice in Northern Ireland. Spine 2002; 27: 406-411.

18. Murtezani A, Govori V, Meka VS, Ibraimi Z, Rrecaj S, Gashi S. A comparison of mckenzie therapy with electrophysical agents for the treatment of work related low back pain: A randomized controlled trial. J Back Musculoskelet Rehabil. 2014 Aug 26. [Epub ahead of print]

19. Kwon M, Shim S, Kim M, Gwak M, Hahm T, Kim G, et al. A Correlation between Low Back Pain and Associated Factors: A Study Involving $772 \mathrm{~Pa}$ tients who had Undergone General Physical Examination. J Korean Med Sci. 2006 Dec; 21(6): 1086-1091.

20. Anderson GBJ. Epidemiological features of chronic low-back pain. Lancet $1999 ; 354: 581-585$.

21. Mangwani J, Giles C, Mullins M, Salih T, Natali C. Obesity and recovery from low back pain : a prospective study to investigate the effect of body mass index on recovery from low back pain. Ann R Coll Surg Engl. 2010 Jan; 92(1): 23-36.

22. Miranda H, Viikari-Juntura E, Martikainen R, Takala EP, Riihimaki H. Individual factors, occupational loading, and physical exercise as predictor of sciatic pain. Spine. 2002; 27(10): 1102-1109. 